\title{
Hazards of parenteral treatment: do particles count?
}

\author{
J W L Puntis, K M Wilkins, P A Ball, D I Rushton, I W Booth
}

\begin{abstract}
After prolonged parenteral nutrition a 12 month old infant died with pulmonary hypertension and granulomatous pulmonary arteritis. A review of necropsy findings in 41 infants who had been fed parenterally showed that two of these also had pulmonary artery granulomata, while none of 32 control patients who died from sudden infant death syndrome had similar findings. Particulate contaminants have been implicated in the pathogenesis of such lesions and these were quantified in amino acid/dextrose solutions and fat emulsions using automated particle counting and optical microscope counting respectively. Parenteral feed infusions compounded for a $3000 \mathrm{~g}$ infant according to standard nutritional regimens were found to include approximately 37000 particles between 2 and $100 \mu \mathrm{m}$ in size in one day's feed, of which $80 \%$ were derived from the fat emulsion. In-line end filtration of intravenous infusions may reduce the risk of particle associated complications. A suitable particle filter is required for use with lipid.
\end{abstract}

\section{(Arch Dis Child 1992;67:1475-7)}

A $1000 \mathrm{~g}$ female infant born at 27 weeks' gestation developed necrotising enterocolitis after a period of respiratory distress and hypoglycaemia. Perforation of the terminal ileum led to laparotomy and formation of an ileostomy, which was closed five months later. Subsequently, an anastomotic stricture and adhesions caused small bowel obstruction requiring further surgery. Septicaemia, recurrent rotavirus infection, and protracted diarrhoea precluded full enteral feeding. She died suddenly and unexpectedly at 12 months of age, having been parenterally fed for much of her life. Striking features at postmortem examination were a granulomatous pulmonary arteritis with some of the arteries being occluded by fibrin, together with dilatation and hypertrophy of the right ventricle secondary to pulmonary hypertension.

Identical lesions in drug offenders are thought to be related to intravenous injection of magnesium trisilicate dust used as a lubricant in drugs intended for oral administration. ${ }^{12}$ Granulomata have also been described in patients who have received large volumes of intravenous fluids, ${ }^{3}$ and they can be reproduced experimentally in rabbits by injection of saline containing particulate matter. ${ }^{4}$ The aims of this study were, therefore, to establish how often pulmonary granulomata could be found at postmortem examination in both patients who had and those who had not received parenteral nutrition, and to determine the number and size of particles in parenteral feeding solutions.

\section{Subjects and methods} NECROPSY STUDY

\section{Subjects}

Postmortem material from all parenterally fed infants from a regional neonatal intensive care unit who had died between 1980 and 1989 were reviewed. Forty one such patients were identified, with a median (range) gestational age of 28 weeks (25-40) and weight $880 \mathrm{~g}(450-2820)$. The most common indication for parenteral nutrition was prematurity and failure to tolerate enteral feeding in association with respiratory distress requiring ventilatory support $(n=38)$; indications in the three remaining patients were necrotising enterocolitis, ischaemic colitis, and ileal atresia. Parenteral nutrition was prescribed according to a standard protocol ${ }^{5}$ with a fluid intake of $150 \mathrm{ml} / \mathrm{kg}$. The median (range) duration of parenteral feeding was 14 days $(1-46)$.

\section{Controls}

Necropsy findings in 32 infants who had died over the same period from sudden infant death syndrome (SIDS) were reviewed. None had received intravenous treatment of any sort.

Although not a double blind study, all postmortem examinations were performed by the same person (DIR). Tissue sections from each lobe of each lung were routinely examined for particulate matter, such as glass or cotton fibres, and for pulmonary vascular granulomata.

\section{PARTICLE STUDY}

Six amino acid/dextrose feeds (Vamin 9 glucose, Kabi Pharmacia; $250 \mathrm{ml}$ in plastic bags) and eight $35 \mathrm{ml}$ aliquots of lipid emulsion (Intralipid $10 \%$, Kabi Pharmacia; in plastic syringes) were constituted according to a standard prescription for neonatal parenteral nutrition, 5 including addition of trace elements, micronutrients, and vitamins. Particles in the feeds were counted in glassware precleaned by washing in laboratory detergent (Decon 90), water, propan-2-ol, trichlorotrifluoroethane, propan-2-ol, and finally water. All washing solutions (except the detergent) were terminally filtered through $0.2 \mu \mathrm{m}$ rated filters fitted to pressurised dispensers.

\section{AUTOMATED PARTICLE COUNTING}

Approximately $100 \mathrm{ml}$ samples of Vamin dextrose solution were run into precleaned bottles (which 
registered $<20$ particles $>2 \mu \mathrm{m}$ in size per $10 \mathrm{ml}$ sample volume when filled with filtered water). Numbers of particles in the ranges $2-5 \mu \mathrm{m}$, 5-10 $\mu \mathrm{m}, 10-25 \mu \mathrm{m}, 25-40 \mu \mathrm{m}$, and 40-100 $\mu \mathrm{m}$ were determined in $10 \mathrm{ml}$ aliquots of these samples using a $\cdot$ Hiac PC-320 automated particle counter with attached D2-60 automatic bottle sampler.

\section{OPTICAL MICROSCOPE COUNTING}

Samples of Intralipid $10 \%$ (35 ml) were filtered through precleaned $0.8 \mu \mathrm{m}$ membranes contained in precleaned filter funnels. The membranes were dried, made transparent, and particles in the range $2-5 \mu \mathrm{m}, 5-10 \mu \mathrm{m}$, 10-25 $\mu \mathrm{m}, 25-40 \mu \mathrm{m}$, and 40-100 $\mu \mathrm{m}$ were counted using a Vickers M17 optical microscope (so that lipid droplets were not counted).

\section{Results}

NECROPSY STUDY

Postmortem examination of the $\mathbf{4 1}$ parenterally fed infants showed two cases of widespread pulmonary granulomata (figure), which had also been identified at the original necropsy. These were located throughout the pulmonary arterial system and showed characteristic features of intimal fibrosis associated with foreign body giant cells with or without associated thrombus formation. In most granulomata it was not possible to identify specific foreign material within the giant cells, but occasionally glass fragments and cotton fibres were easily visible under polarised light. No granulomata or foreign bodies could be found in those patients who died from SIDS.

\section{PARTICLE STUDY}

Particle counts recorded are shown in the table. In one day's parenteral feeding for a $3000 \mathrm{~g}$

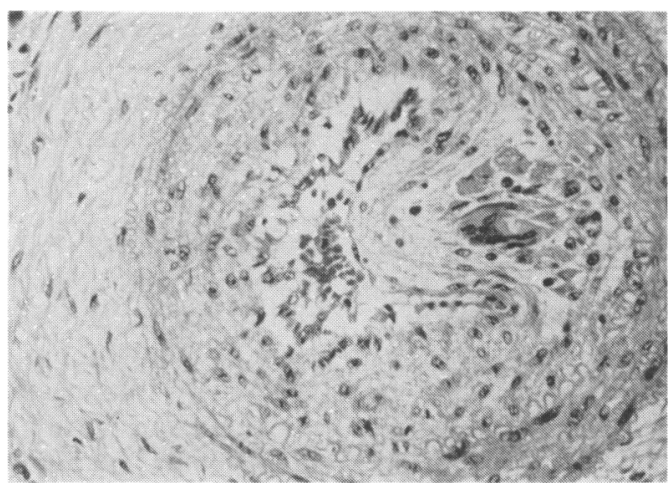

Section of neonatal lung showing granuloma with giant cells in the wall of a pulmonary artery. (Haematoxylin and eosin $\times 300$.) infant, there were approximately 37000 particles between 2 and $100 \mu \mathrm{m}$, with the majority (70\%) being less than $5 \mu \mathrm{m}$ size and only $4 \%$ being above $25 \mu \mathrm{m}$.

\section{Discussion}

Our findings confirm that pulmonary granulomata can be found in a small proportion of patients who have received parenteral fluids. Such granulomata formation has been convincingly related to both particulate contamination of intravenous solutions ${ }^{346}$ and the development of severe cardiovascular disease, ${ }^{12}$ and has been described in infants ${ }^{7}$ as well as adults. We estimate that our index patient with pulmonary hypertension and right heart failure would have received approximately 5 million particles between 2 and $100 \mu \mathrm{m}$ in size from parenteral feed solutions alone.

Early studies of intravenous fluids showed that components of rubber bungs, glass from bottles, and fungal spores were common particulate contaminants together with more exotic finds such as fragments of crustacean. ${ }^{3}$ More recently the hazards of glass fragments ${ }^{8}$ and cotton fibres from alcohol impregnated swabs have been highlighted. ${ }^{9}$ Many particles appear to be organic in nature ${ }^{10}$ and generated by chemical interactions when mixing solutions. Some undoubtedly come from within plastic infusion systems, arising during the process of manufacture. Although there are accepted standards for particle counts in large and small volume parenterals, no such standards exist for infusion systems.

As pulmonary capillaries vary between 8 and $12 \mu \mathrm{m}$ in size, any particle larger than this is likely to be filtered out and retained in the pulmonary vascular bed. Animal experiments with intravenous injection of microspheres indicate that small particles enter the systemic circulation and end up in organs including liver and spleen. ${ }^{11}$ The clinical significance of particles too small to be retained in the lungs is uncertain, although some haemodialysis patients have developed abnormal liver function thought to be a result of silicone particles in the liver derived from siliconised peristaltic blood pumps. ${ }^{12}$

Particulate contamination is known to cause phlebitis in peripheral vessels, a complication significantly reduced by filtration. ${ }^{13}$ Perhaps such physicochemical interaction between particles and vessel walls involves very small as well as large particles. Certainly it is not simply particles large enough to get trapped in vessel lumens that trigger granulomata formulation, as often it is impossible to see any foreign body within the granulomata, while when glass

Mean (SD) particle count (by size) per $10 \mathrm{ml}$ of amino acid/dextrose solution and per $35 \mathrm{ml}$ of Intralipid $10 \%$, with additives compounded according to standard regimen for infant $<10 \mathrm{~kg}$, and dispensed from plastic bags and plastic syringes respectively

\begin{tabular}{|c|c|c|c|c|c|c|}
\hline \multirow[t]{2}{*}{ Feed } & \multirow{2}{*}{$\begin{array}{l}\text { No } \\
\text { of } \\
\text { samples }\end{array}$} & \multicolumn{5}{|c|}{ Partical size $(\mu m)$} \\
\hline & & $2-5$ & $5-10$ & $10-25$ & $25-40$ & $40-100$ \\
\hline $\begin{array}{l}\text { Amino acid/dextrose } \\
\text { Lipid emulsion }\end{array}$ & $\begin{array}{l}6 \\
8\end{array}$ & $\begin{array}{c}151(24) \\
5881(1538)\end{array}$ & $\begin{array}{c}44(13) \\
766(317)\end{array}$ & $\begin{array}{c}13(5) \\
729(406)\end{array}$ & $\begin{array}{c}4(3) \\
418(193)\end{array}$ & $\begin{array}{c}2(2) \\
28(10)\end{array}$ \\
\hline
\end{tabular}


particles can be identified they may be smaller than the vessel lumen itself. There is increasing evidence that interaction between particles and damaged endothelium may be implicated in microcirculatory disturbance which appears to be a key feature of adult respiratory distress syndrome and multiple organ failure in adult intensive care patients. ${ }^{14}$

In-line filtration of amino acid/dextrose mixtures is commonly performed using a $0.2 \mu \mathrm{m}$ rated filter. This type of filter has been developed to retain any microbiological organisms contaminating feeds, ${ }^{15}$ but its usefulness has been questioned ${ }^{16}$ perhaps without consideration of its additional role as particle filter. Any hazards of particulate matter are more likely to occur in patients on long term intravenous treatment. Small infants who have a high fluid intake relative to their weight might be at particular risk. Since Intralipid droplets are similar in size to natural chylomicrons $(0.6-1.6 \mu \mathrm{m})$ and also highly charged they cannot be filtered through a $0.2 \mu \mathrm{m}$ membrane. This means that in our patients, even when the amino acid/dextrose mixture is filtered, four fifths of the particle load within the day's parenteral nutrition fluids is not retained.

Although we have focused attention on parenteral nutrition fluids, it has been estimated that the majority of particles delivered to a patient come from medications together with infusion solutions, ampoules, injection sites, and syringes. ${ }^{17}$ Whereas in-line filtration of parenteral nutrition fluids seems desirable in patients on long term parenteral nutrition, any attempt to reduce the particle load delivered must take account of these other sources.

Increasing recognition that particulate contaminants may cause serious disease provides a persuasive argument for in-line end filtration of all intravenous fluids and injections given to patients needing intensive care. Such a policy could be cost effective through reducing phlebitis associated with peripheral infusions ${ }^{13}$ or in prolonging intravenous administration set life. ${ }^{18}$ Alternatives to glass ampoules ${ }^{20}$ have already been developed and are associated with fewer particles than glass ampoules. The use of hypodermic needles with in-built $5 \mu \mathrm{m}$ filters for drawing up solutions effectively removes many of the glass fragments seen with glass ampoules.

While the precise risks associated with particulate contaminants of intravenous treatment remain uncertain, it is clear that particles themselves are unwanted and unnecessary. There is mounting evidence that they may cause serious disease, particularly in sick patients. Standards for manufacture of administration systems are urgently required. As the manufacturing of small and large volume parenteral nutrition solutions is likely to remain associated with at least some level of particulate contamination, effective filtration will be the only way of preventing adverse clinical consequences. Future developments should include filters suitable for use with lipid emulsions.

We would like to thank Miss J Patterson for invaluable secretarial assistance.

1 Bainborough AR, Jericho KWF. Cor pulmonale secondary to talc granulomata in the lungs of a drug addict. Can Med Assoc F 1970;103:1297-8.

2 Hopkins GB. Pulmonary angiothrombotic granulomatosis in drug offenders. FAMA 1972;221:909-11.

3 Garvan JM, Gunner BW. The harmful effects of particles in intravenous fluids. Med F A ust 1964;ii: 1-5.

4 Garvan JM, Gunner BW. Particulate contamination of intravenous fluids. Br f Clin Prac 1971;25:119-21.

5 Hughes CA. Parenteral nutrition. In: Insley J, ed. A paediatric vade mecum. London: Lloyd Luke, 1982:60-7.

6 Gross MA, Carter CJ. The pathogenic hazard of particulate matter in solutions for intravenous use. Proceedings of a symposium on safety of large volume parenteral solutions. Washington DC: Food and Drug Administration, 1966: 31-7.

7 Sarrut S, Nezelof C. Une complication de la therapeutique intraveineuse: l'arterite pulmonaire macrophagique a cellules geantes. Presse Med 1960;68:375-7.

8 Shaw NJ, Lyall EGH. Hazards of glass ampoules. BMF 1985; 291:1390.

9 Bavikatte K, Hilliard J, Scheiner RL, et al. Systemic vascular cotton fiber emboli in the neonate. 7 Pediatr 1979; 95:614-6.

10 Signoretti EC, Dell'Utri A. Paoletti L, Batisti D, Montanari L. Parenteral solutions: nature of particulate matter. Drug Development and Industrial Pharmacy 1988;14:1-12.

11 Kanke M, Simmons GH, Weiss DL, Bivins BA, DeLuca PP. Kanke M, Simmons GH, Weiss DL, Bivins BA, DeLuca PP.
Clearance of ${ }^{1+1} \mathrm{Ce}$-labelled microspheres from blood and distribution in specific organs following intravenous and intraarterial administration in beagle dogs. $\mathcal{F}$ Pharm Sci 1980;69:755-62.

12 Hunt J, Farthing MJG, Baker LRI, Crocker PR, Levison DA. Silicone in the liver: possible late effects. Gut 1989;30: $239-42$.

13 Falchuk KH, Peterson L, McNeil BJ. Microparticulate induced phlebitis. N Englf Med 1985;312:78-82.

14 Kirkpatrick CJ. Aspekte der Pathogenese des Multiorganversagens. $E C C$ Inter 1990;2:177-82.

15 Holmes CJ, Jundsin RB, Ausman RK, Walter CW. Potential hazards associated with microbial contamination of inline filters during intravenous therapy. F Clin Microbiol 1980; 12:725-31.

16 Silk DBA. Nutritional support in hospital practice. Oxford: Blackwell Scientific, 1983:102-49.

17 Mehrkens HH, Klaus E, Schmitz JE. Moglichkeiten materieller Verunreinigungen durch Zusatzinjektionen. materieller Verunreinigungen durch Zusat
Klin Anasthesiol Intensivther 1977;14:106-13.

18 Cousins D. Cost savings in IV therapy. Care of the Critically Ill 1988;4:30-5.

19 Puntis JWL, Booth IW. The place of a nutritional care team in paediatric practice. Intensive Therapy and Clinical Monitoring 1990;11:132-6.

20 Waller DG, George CF. Ampoules, infusions and filters. BMF 1986;292:714. 